\title{
Adsorptive removal of cationic and anionic dyes from aqueous solution by utilizing almond shell as bioadsorbent
}

\author{
Rim Ben Arfi ${ }^{1} \cdot$ Sarra Karoui $^{1} \cdot$ Karine Mougin $^{2} \cdot$ Achraf Ghorbal $^{1,3}$
}

Received: 23 January 2017/Accepted: 7 August 2017/Published online: 21 August 2017

(C) Springer International Publishing AG 2017

\begin{abstract}
Almond shell is a food waste that is utilized as bioadsorbent for the uptake of Eriochrome Black T (EBT) and Malachite Green (MG) dyes from aqueous solutions. The biomaterial was characterized by specific surface area (BET), scanning electron microscopy, Fourier transform infrared spectroscopy (FTIR), thermogravimetric analysis, and X-ray diffraction. The effects of the initial $\mathrm{pH}$ of solutions, particle size, adsorbent dosage, initial dye concentration, contact time, and temperature on the EBT and MG adsorption were studied using batch contact mode at $22{ }^{\circ} \mathrm{C}$. Rapid sorption dynamics following a second-order kinetic model were shown by kinetic studies. The adsorption equilibrium data were fitted well to the Freundlich isotherm for EBT and MG as anionic and cationic dyes, respectively. The adsorption of pollutants was exothermic $\left(\Delta H^{0}=-1.7 \mathrm{~kJ} \mathrm{~mol}^{-1}\right.$ for EBT and $-32 \mathrm{~kJ} \mathrm{~mol}^{-1}$ for $\mathrm{MG})$. The reaction was accompanied by a decrease in entropy $\left(\Delta S^{0}<0\right.$ for EBT and MG). Negative values of $\Delta G^{0}$ showed the spontaneity of the MG adsorption process. However, positive values of $\Delta G^{0}$ showed that the EBT uptake by almond shell is not a spontaneous reaction. The
\end{abstract}

Electronic supplementary material The online version of this article (doi:10.1007/s41207-017-0032-y) contains supplementary material, which is available to authorized users.

Achraf Ghorbal

achraf.ghorbal.issat@gmail.com

1 Research Unit UR11ES80, National Engineering School of Gabès, University of Gabès, Gabès, Tunisia

2 Institute of Materials Science of Mulhouse, CNRS - UMR 7361, Mulhouse, France

3 Higher Institute of Applied Sciences and Technology of Gabès, University of Gabès, Rue Omar ibn el Khattab, 6072 Gabès, Tunisia results indicate that almond shell is a promising alternative for the biosorption of anionic (EBT) and cationic (MG) dyes from aqueous solutions.

Keywords Almond shell · Eriochrome Black T . Malachite Green · Adsorption · Kinetics · Thermodynamics

\section{Introduction}

During the past decades, dyes have substantially ravaged aquatic environments and human health. Indeed, approximately $15 \%$ of the total dyestuff (over $7 \times 10^{5}$ tons is produced worldwide annually) is lost during the dyeing process in different textile industries and comes out with their waste water (Dutta et al. 2014). Therefore, effective removal of hazardous dyes from polluted water has become a critical point to be resolved. A number of techniques have been adopted to remove dyes, such as chemical precipitation, aerobic and anaerobic microbial degradation, ion exchange, membrane separation, electrochemical treatment, flocculation, reverse osmosis, and adsorption (Li et al. 2015b, 2016). In comparison with other techniques, adsorption could be considered as an effective, attractive, and promising process owing to its ease of operation, simplicity, suitability to treat concentrated dye wastes, selectivity, wide-ranging availability, and inexpensive nature ( $\mathrm{Li}$ et al. 2015a).

In recent years, many adsorbents prepared on the basis of agricultural wastes and by-products such as sugarcane bagasse (Zhang et al. 2011), Luffa cylindrica fibers (Kesraoui et al. 2016), pineapple leaf (Rahmat et al. 2016), or sunflower seed hull (Hameed 2008) have been reported and applied for the removal of ionic and nonionic dye molecules from water.

In recent papers, the utilization of agricultural byproducts as bioadsorbents was widely discussed in terms of 
capacity of pollutant uptake, isotherm, and kinetic models and thermodynamic aspects, revealing that the solution $\mathrm{pH}$, the nature of the dye, and the chemical composition of adsorbents greatly affect the adsorption phenomenon (Módenes et al. 2015).

Regarding the great diversity of cheap, environmentally benign, and abundant agricultural by-products, other efficacious bioadsorbents could be considered as interesting for the uptake of hazardous pollutants from aqueous solutions. So, even if agricultural wastes have no remarkable industrial and commercial use, almond shell could be regarded as a potential low-cost bioadsorbent (Maaloul et al. 2017). As per the literature survey and to the best of our knowledge, not enough work has been reported on the application of almond shells as biosorbents in the uptake of anionic [Eriochrome Black T (EBT)] and cationic [Malachite Green (MG)] dyes (Senturk et al. 2010; Calero et al. 2013; Deniz 2013).

EBT and MG were chosen as model dyes because both are hazardous, carcinogenic, and toxic. Indeed, it is well known that EBT (sodium 1-[1-hydroxynaphthylazo]-6-nitro-2-naphthol-4-sulfonate) is a typical mono-azo anionic dye. EBT is widely used in the textile, paper, printing, food, and pharmaceutical industries, as well as in research laboratories. In addition, MG (4-\{[4-(dimethylamino)phenyl](phenyl)methylidene $\}-N, N$-dimethylcyclohexa-2,5-dien-1-iminium chloride) is one of the most commonly used dyes for silk, paper, cotton, and leather dyeing as well as for the production of paints, varnishes, and printing inks. It is therefore of prime importance to eliminate such toxic pollutants from industrial effluents before they are discharged into the aquatic environment (Gautam et al. 2015).

The purpose of this study was to evaluate the likelihood of using milled Tunisian almond shell (TAS) as a low-cost adsorbent of hazardous dyes. The selected dyes are common pollutants in the environment, but nevertheless they are less studied compared to other dyes such as Methylene Blue (Chairunnisa et al. 2016; Saghanejhad Tehrani and Zare-Dorabei 2016) and Red Congo dyes (Dawood and Sen 2012; Mota et al. 2015). The physicochemical properties and the composition of the prepared bioadsorbents were studied with the help of characterization methods. In addition, the adsorption isotherms, kinetics, and thermodynamic parameters for the removal of EBT and MG dyes by milled almond shells are also discussed.

\section{Experimental}

\section{Materials}

All solvents utilized in this work were of analytical grade and commercially available. EBT and MG were purchased from Panreac AppliChem and Loba Chemicals, respectively, and used without additional purification. Chemical structures and characteristics of EBT and MG are summarized in Table 1. For the adsorption experiments, stock solutions of dyes were prepared by dissolving appropriate quantities of EBT and MG in $1000 \mathrm{~mL}$ of distilled water. The working solutions were freshly prepared by diluting stock solutions $\left(1000 \mathrm{mg} \mathrm{L}^{-1}\right)$. The $\mathrm{pH}$ of solutions was adjusted to the desired values by adding either $0.1 \mathrm{M} \mathrm{HCl}$ and/or $\mathrm{NaOH}$.

\section{Preparation of the bioadsorbent}

Almond shells were supplied by a local farmer and originated from almond trees (Prunus dulcis) cultivated in the region of Sfax (Tunisia). TAS were washed thoroughly with running tap water, rinsed with distilled water, and then crushed into small pieces. Crushed TAS were then air-dried at room temperature (ca. $22^{\circ} \mathrm{C}$ ) for $24 \mathrm{~h}$ followed by an oven drying at $55^{\circ} \mathrm{C}$ until constant weight. They were then milled in a Retsch SM100 mill (Retsch GmbH, Germany). The TAS powder was sieved to obtain various size fractions of less than 100, 100-200, 200-315, 315-400, 400-500, and greater than $500 \mu \mathrm{m}$ using wire sieves with aperture sizes of $0.1,0.2,0.315,0.4$, and $0.5 \mathrm{~mm}$, respectively. Biosorbents were stocked in a desiccator for further use without any additional chemical or physical modifications.

\section{Analysis}

Dye concentration was calculated using a PG T60 UV-Vis spectrophotometer (PG Instruments Ltd., UK) at the maximum wavelength of each dye $(529 \mathrm{~nm}$ for EBT and $616 \mathrm{~nm}$ for MG) based on the linear calibration curve obtained by plotting absorbance toward EBT or MG concentration over the desired concentration range. The $\mathrm{pH}$ of the solutions was measured by an Orion Star A211 pH meter (Thermo Fisher Scientific, USA). The infrared spectra were obtained by a Spectrum Two (PerkinElmer, USA) spectrophotometer using a pyroelectric deuterated glycine sulfate (DTGS) detector. An attenuated total reflection (ATR) attachment with a diamond crystal was used. Measurements were performed in the $450-4000 \mathrm{~cm}^{-1}$ wavenumber range with a resolution of $2 \mathrm{~cm}^{-1}$.

The chemical composition of TAS was determined according to the methods of the Technical Association of Pulp and Paper Industry (TAPPI). The amount of holocellulose (cellulose + hemicelluloses) of the TAS powder was determined according to the titration method (TAPPI T19m-54). The $\alpha$-cellulose was separated from the holocellulose by an alkali extraction using the TAPPI standard 
Table 1 Chemical structures and some properties of EBT and MG dyes used in this study

\begin{tabular}{|c|c|c|}
\hline Dyestuff & Eriochrome Black T (EBT) & Malachite Green (MG) \\
\hline IUPAC name & $\begin{array}{l}\text { Sodium 1-[1-Hydroxynaphthylazo]-6- } \\
\text { nitro-2-naphthol-4-sulfonate }\end{array}$ & $\begin{array}{l}\text { 4-[(4-Dimethylaminophenyl)- } \\
\text { phenyl-methyl]- N,N-dimethyl- } \\
\text { aniline }\end{array}$ \\
\hline C.I. number & 14645 & 42000 \\
\hline Appearance & Dark red/brown powder & Green crystalline powder \\
\hline Empirical formula & $\mathrm{C}_{20} \mathrm{H}_{12} \mathrm{~N}_{3} \mathrm{NaO}_{7} \mathrm{~S}$ & $\mathrm{C}_{23} \mathrm{H}_{25} \mathrm{ClN}_{2}$ \\
\hline Molecular weight $\left(\mathrm{g} \mathrm{mol}^{-1}\right)$ & 461.38 & 364.91 \\
\hline Charges in aqueous solution & Negative & Positive \\
\hline \multicolumn{3}{|l|}{ Molecular structure } \\
\hline$\lambda_{\max }(\mathrm{nm})$ & 529 & 616 \\
\hline
\end{tabular}

method T203 om-88. The amount of lignin in the TAS powder was quantified by reaction with sulfuric acid according to the TAPPI T222 om-88 standard method. Measurements were performed in triplicate.

Surface morphology observations of the bioadsorbents were performed using scanning electron microscopy (SEM) employing an XL30 device (Philips Co., Netherlands) operated at a $15-\mathrm{kV}$ accelerating potential. X-ray diffraction (XRD) measurements were performed on an X'Pert Pro X-ray diffractometer (PANalytical, Netherlands). The diffracted intensity of the $\mathrm{Cu} \mathrm{K} \alpha$ radiation ( $\lambda=0.154 \mathrm{~nm}, 45 \mathrm{kV}, 40 \mathrm{~mA}$ ) was evaluated in the $10-60^{\circ} 2 \theta$ range. The BET surface areas of biosorbents were evaluated using an ASAP 2420 (Micrometrics Instrument Corp., USA) surface area analyzer where the utilized gaseous adsorbate was $\mathrm{N}_{2}$. Thermogravimetric (TG) and derivative thermogravimetric (DTG) curves of TAS were obtained by using a thermogravimetric analyzer (TGA/DSC3+, Mettler Toledo, USA) under the following experimental conditions: initial temperature $30{ }^{\circ} \mathrm{C}$, final temperature $900{ }^{\circ} \mathrm{C}$, heating rate $10{ }^{\circ} \mathrm{C} \mathrm{min}{ }^{-1}$, and nitrogen flow rate $100 \mathrm{~mL} \mathrm{~min}{ }^{-1}$.

The $\mathrm{pH}_{\mathrm{zpc}}$ of the bioadsorbent was obtained by the powder addition method (Chan et al. 2016).

A $0.01 \mathrm{M} \mathrm{NaCl}$ solution was prepared, then the initial $\mathrm{pH}$ was adjusted in the 2-12 range by adding either $0.1 \mathrm{~N}$ $\mathrm{HCl}$ and/or $\mathrm{NaOH}$. Fifty-milliliter aliquots of he prepared $0.01 \mathrm{M} \mathrm{NaCl}$ solutions were taken in 250-mL Erlenmeyer flasks. Then, $0.2 \mathrm{~g}$ of the bioadsorbent was suspended in each solution. The suspensions were left for $24 \mathrm{~h}$, and the final $\mathrm{pH}$ was then evaluated (Banerjee et al. 2016). The point of zero charge $\left(\mathrm{pH}_{\mathrm{zpc}}\right)$ is the point where the $\Delta \mathrm{pH}\left(=\mathrm{pH}_{\text {final }}-\mathrm{pH}_{\text {initial }}\right)$ is zero (Leng et al. 2015).

\section{Batch biosorption experiments}

The adsorption study of EBT and MG on the TAS powder was performed by the batch equilibrium method. A predetermined amount of TAS $(0.1 \mathrm{~g})$ was suspended in $50 \mathrm{~mL}$ of various concentrations of the biosorbent in a stoppered 100-mL flask and maintained under isothermal conditions at $320 \mathrm{rpm}$. Initial concentrations of TAS in the experimental environment were adjusted to the desired values in the $0.1-12 \mathrm{~g} \mathrm{~L}^{-1}$ range. The adsorption study was performed at 22,30 , and $40^{\circ} \mathrm{C}$. The resultant solution was then centrifuged (Z $32 \mathrm{HK}$, HERMLE Labortechnik, Germany) at $10,000 \mathrm{rpm}$ for $5 \mathrm{~min}$ to extract the TAS powder from the liquid phase. The concentration of EBT and MG in the solution was evaluated spectrophotometrically at 529 and $616 \mathrm{~nm}$, respectively, after an equilibrium time of $300 \mathrm{~min}$.

The percentage of EBT and MG dyes removed was computed using the Eq. 1:

Dye removal $(\%)=100 \times\left(C_{0}-C_{\mathrm{e}}\right) / C_{0}$.

The amount of dye uptake $q_{\mathrm{e}}$ (mg dye per gram of biosorbent) by the TAS was estimated by Eq. 2: 
$q_{\mathrm{e}}=\left(C_{0}-C_{\mathrm{e}}\right) V / W$,

where $C_{0}$ and $C_{\mathrm{e}}$ are respectively initial and equilibrium dye concentration $\left(\mathrm{mg} \mathrm{L}^{-1}\right), V$ is the volume of the solution added (L), and $W$ is the amount of almond shell powder (g).

In experiments of batch kinetic biosorption, a predetermined amount $(0.5 \mathrm{~g})$ of the bioadsorbent and $250 \mathrm{~mL}$ dye solution $\left(100 \mathrm{mg} \mathrm{L}^{-1}\right)$ were placed in a stoppered $500-\mathrm{mL}$ conical flask and maintained at $22 \pm 2{ }^{\circ} \mathrm{C}$ and under an agitation rate of $320 \mathrm{rpm}$. At different time intervals, the solution was separated from the bioadsorbent and concentrations of EBT and MG were determined spectrophotometrically at 529 and $616 \mathrm{~nm}$, respectively. The amount of the biosorbed dye, $q_{\mathrm{t}}\left(\mathrm{mg} \mathrm{g}^{-1}\right)$ at time $t$ on the TAS, was computed by Eq. 2 (Bhatt et al. 2012). All experiments were carried out at least two times and mean values were considered for the purpose of evaluation.

\section{Error analysis}

The validity of each model was analyzed by the coefficient of determination $\left(R^{2}\right)$ and the Person's Chi-square test $\left(\chi^{2}\right)$ (Eq. 3) as well as the normalized standard deviation $\Delta q$ (Eq. 4):

$\chi^{2}=\left(q_{\mathrm{e}, \mathrm{exp}}-q_{\mathrm{e}, \mathrm{cal}}\right)^{2} / q_{\mathrm{e}, \mathrm{cal}}$

$\Delta q(\%)=100 \sqrt{\sum\left[\left(q_{\mathrm{e}, \exp }-q_{\mathrm{e}, \mathrm{cal}}\right) / q_{\mathrm{e}, \mathrm{exp}}\right]^{2} /(N-1)}$,

where $q_{\mathrm{e}, \text { exp }}$ is the experimental value of biosorption capacity $\left(\mathrm{mg} \mathrm{g}^{-1}\right), q_{\mathrm{e}, \mathrm{cal}}$ is the calculated biosorption capacity $\left(\mathrm{mg} \mathrm{g}^{-1}\right)$, and $n$ is the number of measurements. The best suitable model can be determined when the $R^{2}$ value is equal to or near 1 , whereas the Chi-square test $\left(\chi^{2}\right)$ and the normalized standard deviation $(\Delta q)$ are as small as possible.

\section{Results and discussion}

\section{Characterization of the bioadsorbent}

The functional groups responsible for the adsorption of EBT and MG on the cell surfaces of adsorbent are studied by FTIR spectrophotometry. The FTIR spectra of TAS, EBT-loaded TAS, and MG-loaded TAS are shown in Fig. 1. The spectrum of TAS before the dye sorption processes (Fig. 1a) contains a series of peaks associated with functional groups in the TAS lignocellulosic structure. A characteristic broad band of stretching vibrations of $\mathrm{C}-\mathrm{H}$ and $\mathrm{O}-\mathrm{H}$ groups in the $3650-3000 \mathrm{~cm}^{-1}$ range shows the principal functional groups found in lignocellulosic materials. The FTIR spectrum of TAS shows a characteristic peak at $1731 \mathrm{~cm}^{-1}$ from the $\mathrm{C}=\mathrm{O}$ stretching of methyl ester and carboxylate groups in pectin. This peak could be also associated with the ester linkage of the lignin and hemicellulose carboxylic group or hemicellulose acetyl and uronic ester groups (Xiao et al. 2015). Peaks in the wavenumber range from 1240 to $1450 \mathrm{~cm}^{-1}$ could be attributed to TAS surface structures containing $\mathrm{C}-\mathrm{O}-\mathrm{H}, \mathrm{C}-$ $\mathrm{O}$, and $\mathrm{C}-\mathrm{H}$ bonds that are associated with carboxylic acids (Módenes et al. 2015). In the "fingerprint" region, absorbance bands are assigned to the lignin at $2850 \mathrm{~cm}^{-1}$ corresponding to the $\mathrm{C}-\mathrm{H}$ stretching vibration and in the range $1615-1500 \mathrm{~cm}^{-1}$ originating from aromatic skeletal vibration. The double peak at 2920 and $2852 \mathrm{~cm}^{-1}$ could be attributed, respectively, to the symmetric and asymmetric $\mathrm{C}-\mathrm{H}$ stretching vibrations in methyl and methylene of aliphatic chains. The peaks at 3270,2902 , and $710 \mathrm{~cm}^{-1}$ may be related to the existence of cellulose $I_{\beta}$ (monoclinic crystalline structure of cellulose) in the TAS material. These results were in good agreement with the chemical composition of the TAS powder. The major components of TAS were lignin $(30.1 \pm 0.5 \mathrm{wt} \%)$ and $\alpha$-cellulose $(29.9 \pm 0.7 \mathrm{wt} \%)$. Hemicellulose was another major component $(25.1 \pm 0.7 \mathrm{wt} \%)$.

Even if it is difficult to identify in which adsorption sites the EBT and MG dyes were linked to the TAS particle surfaces, a signature of dye adsorptions may be related to the modification of peak bands through spectra after the biosorption. Peak bands in ATR-FTIR spectra of TAS before and after the adsorption of dyes are comparatively different, suggesting that the bonding of pollutants molecules to TAS particle surfaces may be at the origin of a slight alteration of peak bands (Módenes et al. 2015). The TAS FTIR spectrum differed from those obtained for the

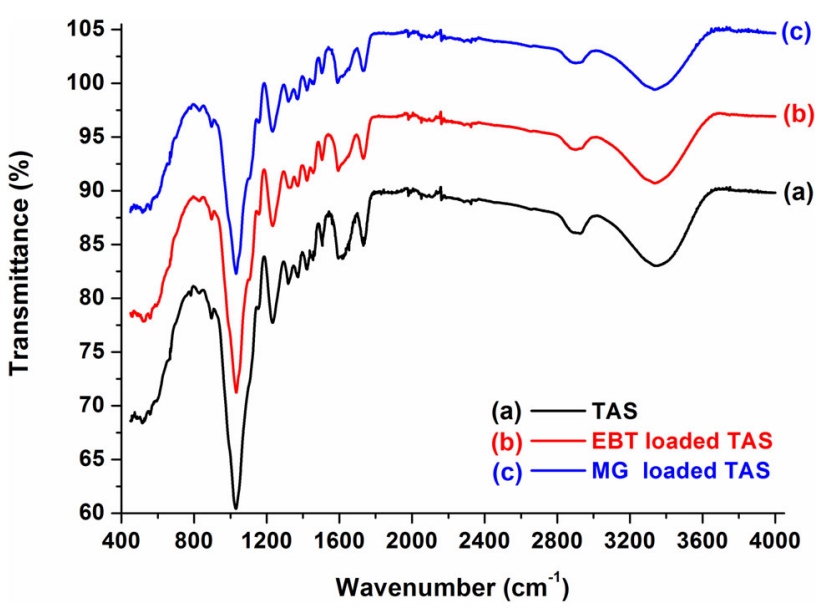

Fig. 1 FTIR spectra of $a$ TAS powder, $b$ EBT-loaded TAS, and $c$ MG-loaded TAS 
EBT and MG dye sorption (Fig. 1b, c), principally at the $1733-782 \mathrm{~cm}^{-1}$ range, identifying some altered peak bands at 1733, 1660-1580, 1508, 1340-1315, 1107, and $782 \mathrm{~cm}^{-1}$.

The textural characteristics of adsorbents, such as the pore volume and the surface area, play a key role in the biosorption process of pollutant molecules. The BET surface area characterization showed that the bioadsorbent has a specific surface area of about $1.65 \mathrm{~m}^{2} \mathrm{~g}^{-1}$. In addition, for the porosity measurement, the Barrett-Joyner-Halenda (BJH) pore size distribution was deduced from the $\mathrm{N}_{2}$ isotherm which indicated that about $30 \%$ of pores fall into the macroporous category (greater than $50 \mathrm{~nm}$ ). The TAS characterization showed that the average pore diameter and pore volume were equal to $34.3 \mathrm{~nm}$ and $0.0086 \mathrm{~cm}^{3} \mathrm{~g}^{-1}$, respectively. The large number of macropores with a significant volume of pores facilitates the removal of an important amount of EBT and MG molecules from the aqueous solution (Banerjee et al. 2016).

The X-ray diffractogram (Fig. 1Sa in supplemental material) of TAS powder clearly shows peaks generally attributed to cellulosic materials at $2 \theta$ equal to $16^{\circ}, 22^{\circ}$, and $34^{\circ}$ after reflections on the (101), (002), and (040) planes, respectively (Banerjee et al. 2016). The broad and diffuse appearance of the peaks suggests the amorphous nature of the sample. Figures $1 \mathrm{Sb}$ and $1 \mathrm{Sc}$ in the supplemental material represent diffraction peaks after EBT and MG uptake. It could be observed that the intensity of peaks becomes slightly weaker which may be due to surface adsorption of EBT and MG onto TAS particles. However, no change in the position of peaks was noted which suggests that no phase transformation was observed after EBT and MG dye adsorption (Banerjee et al. 2016).

The degradation pattern and thermal stability of the TAS were studied by thermogravimetric analysis (TGA). Thermogravimetric (TG) and derivative thermogravimetric (DTG) curves of TAS are shown in Fig. 2S (attached in supplemental material). The initial weight loss $\left(60-120{ }^{\circ} \mathrm{C}\right)$ was ascribed to the desorption of water molecules from TAS particles. The weight loss in the initial steps was about $8 \%$. The second weight loss $(31 \%)$ between 210 and $330{ }^{\circ} \mathrm{C}$ could be attributed to the depolymerization of hemicelluloses, the cleavage of glycosidic linkages of cellulose, and the decomposition of some portions of lignin. The weight loss (41\%) between 330 and $400{ }^{\circ} \mathrm{C}$ was ascribed to the deterioration of cellulose and lignin. As a result of the complexity of lignin's structure, its degradation took place above $400{ }^{\circ} \mathrm{C}$ (Ali et al. 2016).

Surface morphologies of native and dye-loaded TAS were investigated by SEM. The SEM images of TAS, EBT-loaded TAS, and MG-loaded TAS are shown in Fig. $2 \mathrm{a}-\mathrm{d}$, respectively. Figure $2 \mathrm{a}$ and $\mathrm{b}$ reveal the porous characteristics and surface texture of TAS particles. It is apparent in the micrographs that the bioadsorbent is porous and a few well-developed cavernous porous structures were easily seen. These deep large sized pores most likely play a major role in the accommodation of dye molecules from liquid phase to solid surface. Figures $2 \mathrm{c}$ and $\mathrm{d}$ show that the change in textural properties of TAS after EBT and MG adsorption, respectively, is due to the accumulation of dyes onto the bioadsorbent surface indicating that the adsorption phenomena occurred.

The evaluation of the $\mathrm{pH}_{\mathrm{zpc}}$ of the bioadsorbent gives an idea about the electrical neutrality of the material at a specific $\mathrm{pH}$ value. In this work, the $\mathrm{pH}_{\mathrm{zpc}}$ of TAS particles was found to be 5.3 (Fig. 3).

\section{Effect of particle size}

The biosorption of EBT and MG dyes was studied at six various particle sizes, greater than 500, 500-400, 400-315, 315-200, 200-100, and less than $100 \mu \mathrm{m}$. The dye uptake at the aforementioned particle sizes was 24.98, 25.89, 25.76, 26.80, 27.06, and 30.68\% for EBT and 75.74, 85.32, $88.91,92.10,93.86$, and $96.73 \%$ for MG, respectively.

The results in Fig. 4 show that for both dye solutions, the decrease in TAS particle size increases the dye removal. It could be easily deduced that the decrease of the TAS particle size leads to a better accessibility to pores and a larger exposed surface area. Indeed, the number of diffusion paths is increased as a consequence of exposed channels on the particle surface. Consequently, the ability of molecules to penetrate internal pores of TAS particles is very high and the number of adsorption sites is increased, thus resulting in the improvement of the dye uptake from solutions (Ali et al. 2016). All further experiments were carried out with TAS particle size less than $100 \mu \mathrm{m}$ as these showed sufficient adsorption capacity.

\section{Effect of almond shell powder dosage}

The effect of the TAS concentration on dye uptake was studied for 11 adsorbent dosages in the $0.1-12 \mathrm{~g} \mathrm{~L}^{-1}$ range. Figure 5a shows that the adsorbed MG concentration increased from 46 to $97 \mathrm{mg} \mathrm{L}^{-1}$ while the quantity of the adsorbed dye per unit mass diminished from 464 to $8 \mathrm{mg} \mathrm{g}^{-1}$ by increasing the concentration of the bioadsorbent from 0.1 to $12 \mathrm{~g} \mathrm{~L}^{-1}$. The same tendency was also noticed for the EBT dye as shown in Fig. 5b. Indeed, it has previously been reported that an increase in the biosorbent concentration leads to an increase in the number of available sorption sites and therefore results in an increase of biosorbed dye concentration (Lin et al. 2009). However, TAS particle aggregation could result from a high biosorbent concentration. Such biomass aggregation may imply a 
Fig. 2 SEM images of a, b TAS powder, c EBT-loaded TAS, and $\mathbf{d}$ MG-loaded TAS
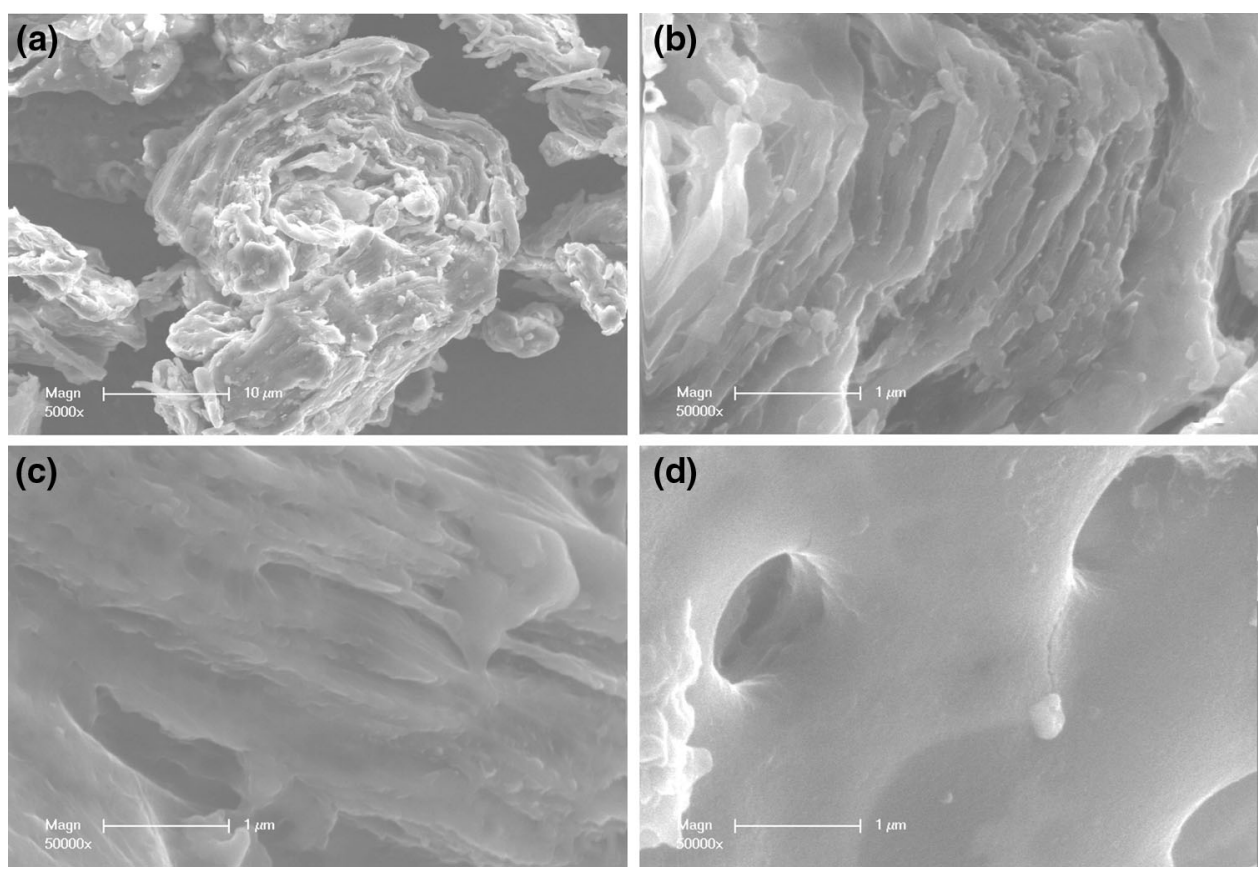

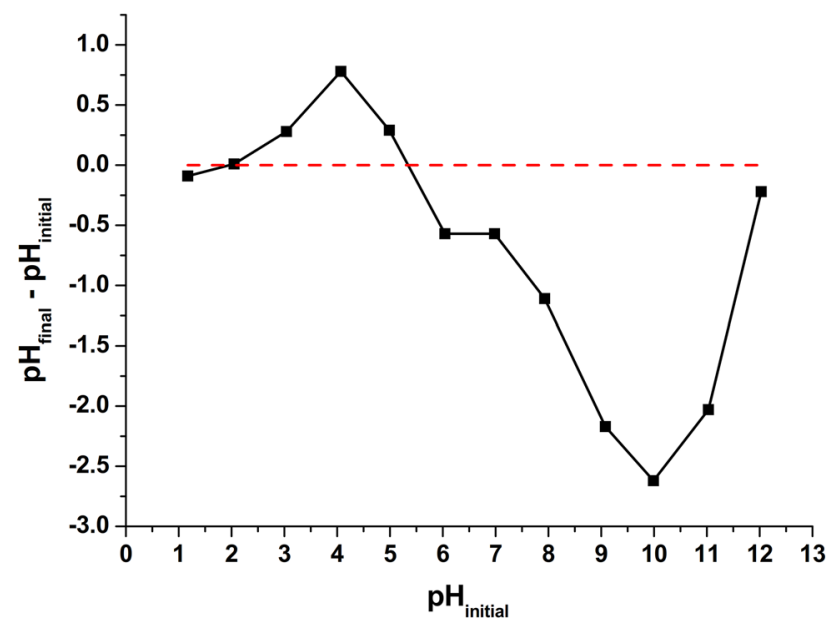

Fig. $3 \mathrm{pH}_{\mathrm{zpc}}$ determination curve

decrease in the total surface area of the bioadsorbent and an increase in the diffusional path length, thus causing a decrease in the quantity of a dye removed per unit weight of TAS (Özer et al. 2005). Therefore, taking the elimination efficiency of EBT and MG dyes and economy into consideration at the same time, a dosage of $2 \mathrm{~g} \mathrm{~L}^{-1}$ was selected for further studies.

\section{Effect of $\mathbf{p H}$}

The $\mathrm{pH}$ is one of the parameters that greatly affect both aqueous chemistry and surface active sites of the bioadsorbents. The removal of EBT and MG dyes at various $\mathrm{pH}$ is depicted in Fig. 6. The influence of the aqueous

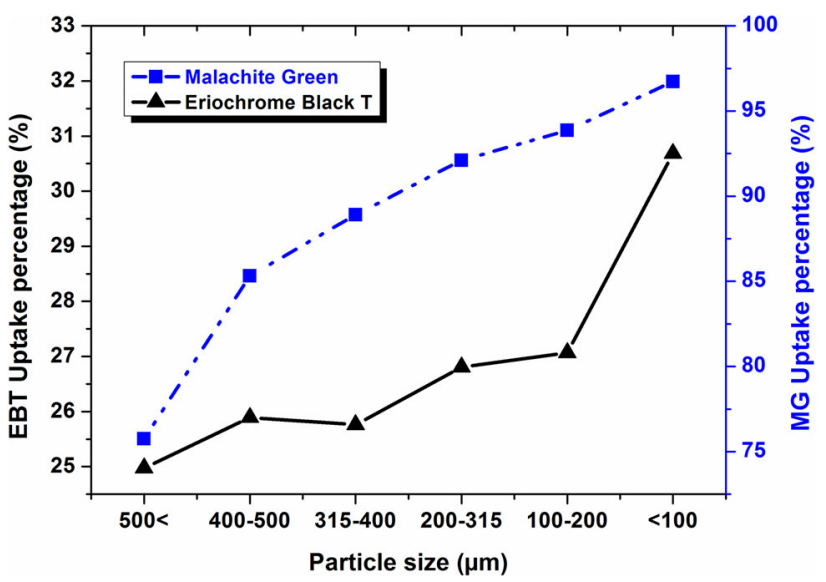

Fig. 4 Effect of TAS particle size on EBT and MG adsorption

environment $\mathrm{pH}$ on the bioadsorption was studied by changing the $\mathrm{pH}$ in the $2-11$ range.

The $\mathrm{pH}_{\mathrm{zpc}}$ of TAS is about 5.3 as observed from the Fig. 3 . At $\mathrm{pH}$ higher than $\mathrm{pH}_{\mathrm{zpc}}$ the bioadsorbent surface has a negative charge and at lower $\mathrm{pH}$ it has a positive charge. As seen in Fig. 6, the EBT uptake capacity at higher pH was lower than that at lower $\mathrm{pH}$, which could be interpreted as being due to the surface charge of the TAS. Below the $\mathrm{pH}_{\mathrm{zpc}}$, the TAS surface (mainly oxygen-containing groups linked to the $\mathrm{H}^{+}$) is positively charged and anionic EBT dye adsorption occurs easily (Leng et al. 2015). On the contrary, when the TAS surface is negatively charged at $\mathrm{pH}>\mathrm{pH}_{\mathrm{zpc}}$, the electrostatic repulsion between negatively EBT species and negatively charged TAS is increased, and this results in a decrease of the anionic dye biosorption (Attallah et al. 2016). 

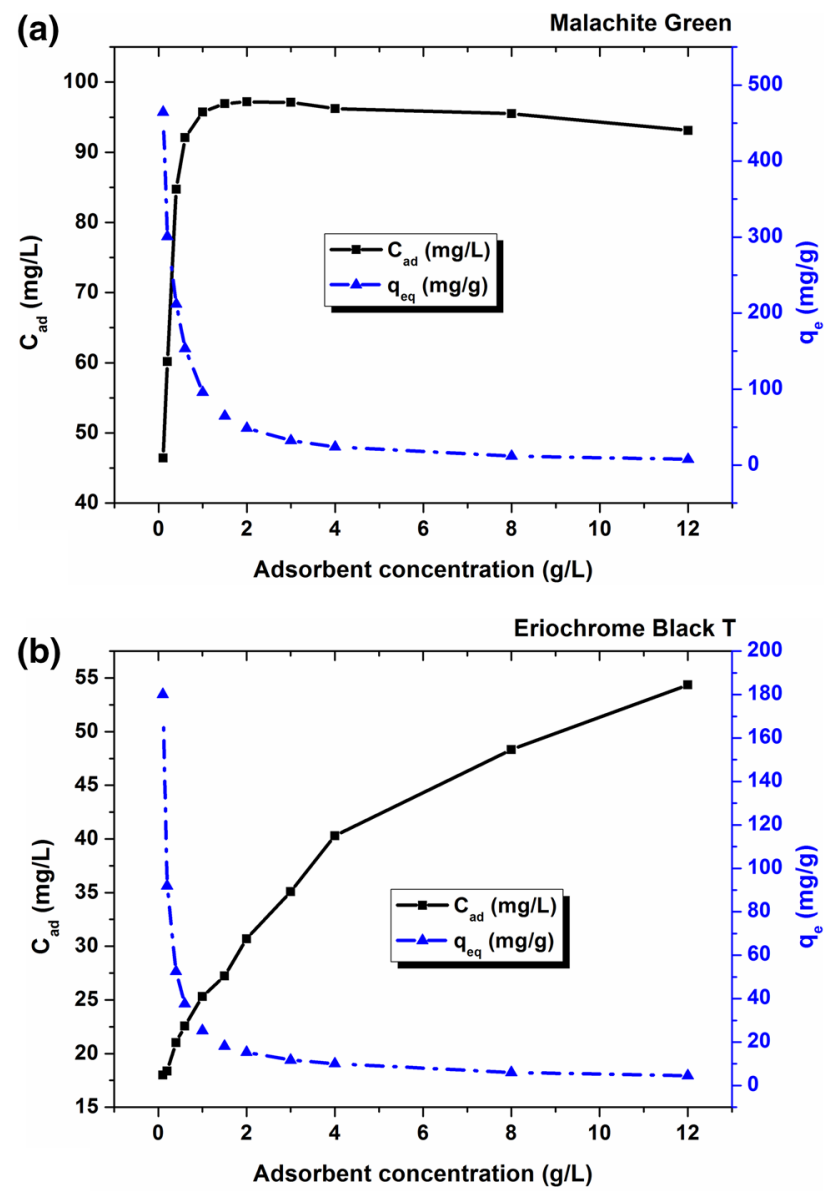

Fig. 5 Effect of the biosorbent dosage on the biosorption of a MG and $\mathbf{b}$ EBT by TAS

In theory, considering the electrostatic interaction between the dye and the adsorbent, the maximum adsorption efficiency for MG should be obtained at around the $\mathrm{pH}$ value of 6 . However, a consistent amount of MG uptake (around $48.5 \mathrm{mg} \mathrm{g}^{-1}$ ) was observed over the whole $\mathrm{pH}$

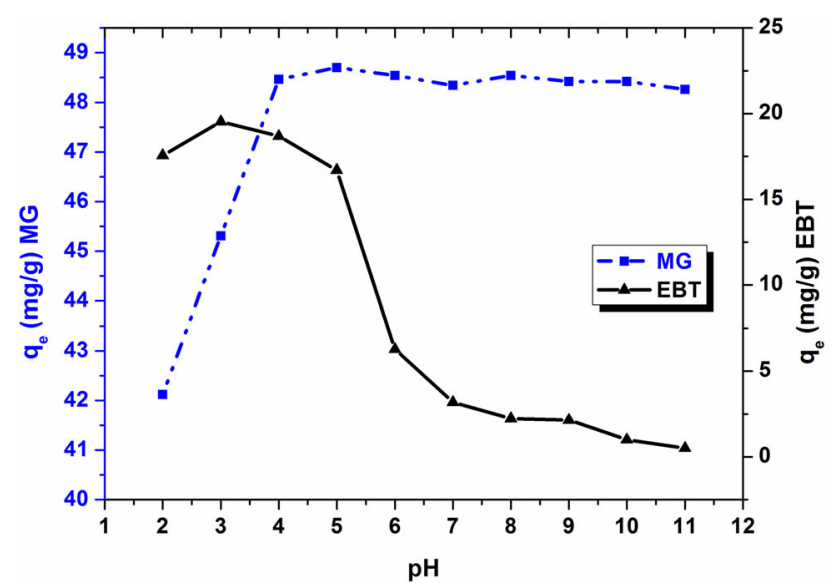

Fig. 6 Effect of solution $\mathrm{pH}$ on the biosorption of EBT and MG by TAS range from 4 to 11 . Thus, one can say that the adsorption process of MG was not mainly controlled by the electrostatic interaction, suggesting existence of $\pi-\pi$ stacking interaction and/or hydrophobic interactions between the triarylmethane dye and the lignocellulosic material. In addition, low $\mathrm{pH}$ values $(\mathrm{pH}<4)$ were disadvantageous for MG uptake by TAS, which could be attributed to the competition between the excess of $\mathrm{H}^{+}$ions and the cationic dye for binding sites (Attallah et al. 2016).

\section{Effect of initial dye concentration}

Figure 7 shows that the quantity of MG and EBT adsorbed increased (from 12 to $95 \mathrm{mg} \mathrm{g}^{-1}$ and from 5 to $31 \mathrm{mg} \mathrm{g}^{-1}$, respectively) with the increase of the initial dye concentration (25-200 $\mathrm{mg} \mathrm{L}^{-1}$ ). This occurred because, at higher initial concentrations, the concentration gradient between the bulk solution and the bioadsorbent surface is higher, thus promoting external mass transfer. In parallel, at high values of the initial dye concentration, internal mass transfer is promoted. A similar tendency was reported by Pavan et al. (2014).

\section{Effect of contact time}

The effect of the contact time on EBT and MG adsorption by TAS at $\mathrm{pH} 4.8 \pm 0.2$, temperature of $22{ }^{\circ} \mathrm{C}$, and bioadsorbent dosage of $2 \mathrm{~g} \mathrm{~L}^{-1}$ is given in Fig. 8. This result indicates that the biosorption efficiency for all initial EBT and MG concentrations in the $25-200 \mathrm{mg} \mathrm{L}^{-1}$ range increases and then becomes constant (at equilibrium) as a function of the contact time. Indeed, it is possible to observe in Fig. 8, that for all dye solutions (EBT and MG) more than $96 \%$ of saturation was achieved within $15 \mathrm{~min}$, while only $3 \%$ was adsorbed until $300 \mathrm{~min}$. This occurred

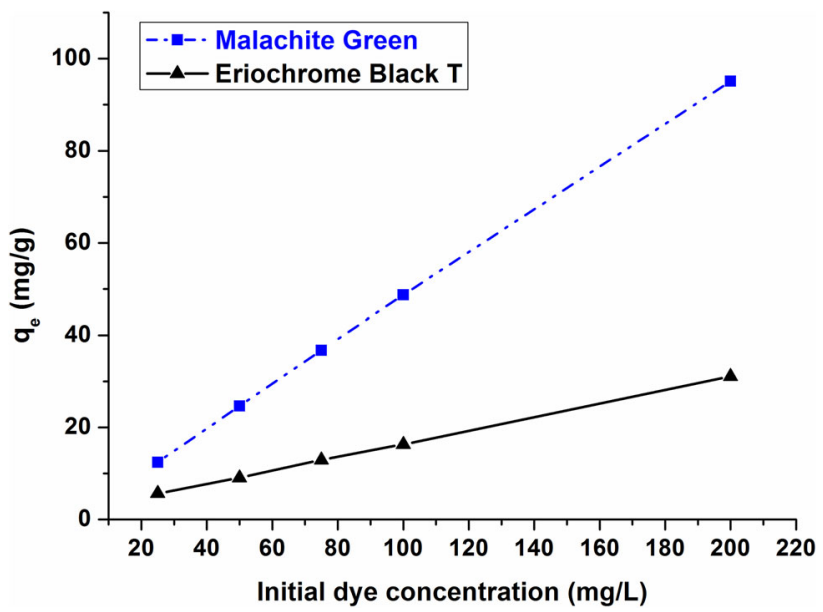

Fig. 7 Effect of the EBT and MG dye concentration on the biosorption capacity $\left(q_{\mathrm{e}}\right)$ using TAS 
because, at the initial adsorption stages, TAS has a large available surface area, compared with the concentration of dyes, favoring a high biosorption rate. However, after initial adsorption stages (after $15 \mathrm{~min}$ ) a competition occurred between dye molecules for the adsorption sites on the surface of TAS, resulting in a decrease in the adsorption rate (Santos and Boaventura 2016).

\section{Biosorption kinetics}

To identify the mechanism of bioadsorption, the removal rate, and the control of the steps involved in the process, two kinetic models (the pseudo-first and pseudo-second order) can be adopted. The pseudo-first-order kinetic model (Lagergren 1898) is given by Eq. 5:

$\ln \left(q_{\mathrm{e}}-q_{t}\right)=\ln q_{\mathrm{e}}-k_{1} t$,

where $k_{1}$ is the pseudo-first-order rate constant $\left(\min ^{-1}\right)$. The $k_{1}$ and $q_{\mathrm{e}, \text { cal }}$ parameters can be determined from the slope and intersection of the lines of $\ln \left(q_{\mathrm{e}}-q_{\mathrm{t}}\right)$ versus $t$.

The pseudo-second-order kinetic model (Ho and McKay 1999) is given by Eq. 6:

$t / q_{t}=1 / k_{2} q_{\mathrm{e}}^{2}+t / q_{\mathrm{e}}$

where $k_{2}$ is the pseudo-second-order rate constant $\left(\mathrm{g} \mathrm{mg}^{-1} \mathrm{~min}^{-1}\right)$. Similarly to the pseudo-first-order kinetic model, the $k_{2}$ and $q_{\mathrm{e}, \mathrm{cal}}$ parameters were deduced from the linear and angular coefficients of the equations formed by regressing $t / q_{\mathrm{t}}$ versus $t$, respectively. These values are summarized in Table 2.

The linear fits of the kinetics results (Table 2) reflect that the pseudo-second-order model exhibits higher $R^{2}$ and lower $\Delta q$ and $\chi^{2}$ values, compared to the pseudo-first-order model. In addition, equilibrium adsorption capacities computed on the basis the pseudo-second-order model are in agreement with the experimental data for both dyes. This proves that bioadsorption kinetics are well described by the pseudo-second-order model and are dependent on the

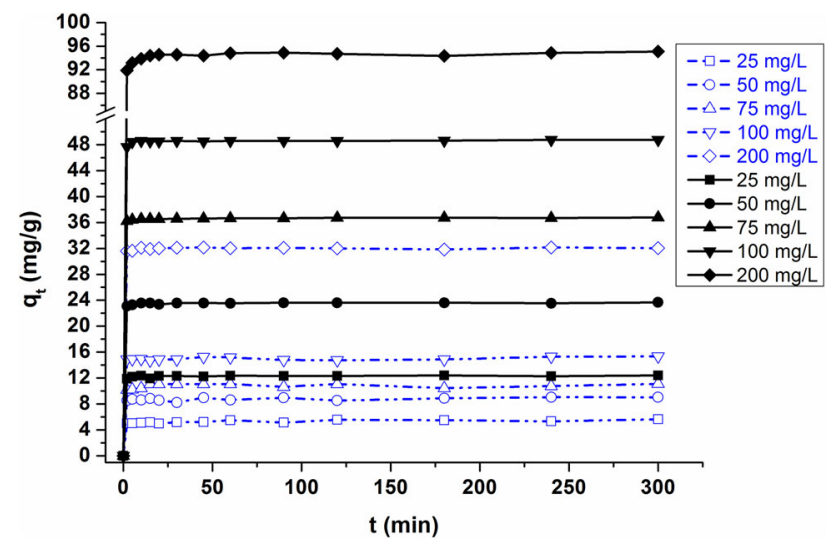

Fig. 8 Effect of contact time on biosorption of EBT and MG by TAS quantity of the dye taken up by the bioadsorbent and the amount adsorbed at equilibrium.

In this work, the intraparticle mass transfer diffusion model (Weber and Morris 1963) was investigated.

$q_{t}=k_{\mathrm{id}} t^{0.5}+C_{i}$,

where $i$ is the number of the linear piecewise function, $k_{\mathrm{id}}$ $\left(\mathrm{mg} \mathrm{g}^{-1} \mathrm{~min}^{-1 / 2}\right)$ is the intraparticle diffusion rate constant, and $C_{i}\left(\mathrm{mg} \mathrm{g}^{-1}\right)$ is the intercept related to the boundary layer thickness.

If the data of the entire adsorption process fits well with the intraparticle diffusion ( $i$ is only equal to 1 ) and $C$ is zero, the intraparticle diffusion is the unique limiting step; otherwise, the larger the intercept, the greater the contribution of the film diffusion in the rate controlling. As shown in Fig. 3S (in supplemental material), the whole EBT and MG adsorption processes show two linear sections in a curve, suggesting multiple steps take place during the bioadsorption process. The piecewise fitting parameters of the intraparticle diffusion are listed in Table 3. The values of $C_{i}$ for each linear portion are not zero, showing that intraparticle diffusion participates in EBT and MG dye biosorption, but is not the sole rate-controlling step. Indeed, film diffusion may also be involved in the biosorption process. At the beginning of biosorption (the first segment in Fig. 3S), film diffusion drives the mass transfer of dyes from the bulk solution to the external surface of TAS particles. In the second stage (the second segment in Fig. 3S) of the biosorption process, equilibrium is reached and the intraparticle diffusion fades out the biosorption of dyes molecules (Leng et al. 2015).

\section{Biosorption isotherms}

Isotherm studies may give an idea about the way that adsorbates interact with bioadsorbents, which is the main element for designing a desired environment of adsorption. Three well-known models were utilized in this work so as to describe the adsorption process, namely Freundlich (Eq. 8) (Freundlich 1906), Langmuir (Eq. 9) (Langmuir 1918), and Temkin (Eq. 10) (Temkin and Pyzhev 1940) isotherm models:

$\ln q_{\mathrm{e}}=\ln k_{\mathrm{F}}+\frac{1}{n} \ln C_{\mathrm{e}}$

$1 / q_{\mathrm{e}}=1 / q_{\mathrm{m}}+1 / k_{\mathrm{L}} q_{\mathrm{m}} C_{\mathrm{e}}$

$q_{\mathrm{e}}=k_{\mathrm{T}} \ln C_{\mathrm{e}}+k_{\mathrm{T}} \ln f$,

where $q_{\mathrm{m}}\left(\mathrm{mg} \mathrm{g}^{-1}\right)$ is the theoretical maximum adsorption capacity; $k_{\mathrm{L}}, k_{\mathrm{F}}$, and $k_{\mathrm{T}}$ are the adsorption constants of Langmuir, Freundlich, and Temkin models, respectively; $n$ and $f$ are the Freundlich linearity index and the Temkin isotherm constant, respectively. 


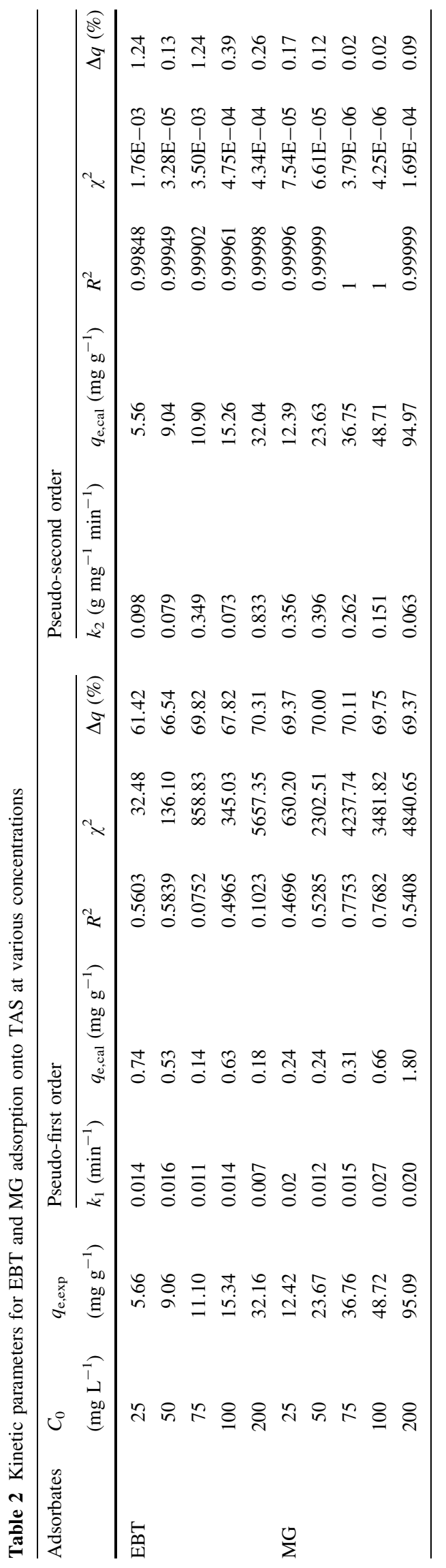

It is well known that the Langmuir adsorption isotherm is established on the basis of the hypothesis that pollutants molecules are bound to the adsorbent surface at specific and homogenous sites in the absence of any interaction between them. In addition, all active sites have the same affinity for dye molecules and the biosorption attains its maximum level after the appearance of a monolayer of pollutant molecules on the bioadsorbent surface. This model usually describes the equilibrium uptake isotherms of homogeneous surfaces. Contrary to the Langmuir model, the Freundlich model presupposes that the surface energy of the bioadsorbent is heterogeneous. Indeed, the Freundlich adsorption isotherm is established on the basis of the hypothesis that the strength of binding decreases with the increasing degree of bonding to active sites. Moreover, it is presupposed that the first occupied active sites are those with strongest binding energies. The value of $n$ informs about the heterogeneity degree of the biosorption sites. In fact, as the slope $1 / n$ tends toward zero, the surface site heterogeneity increases. The Temkin model is an appropriate model for the sorption based on strong electrostatic interactions between opposite charges (Liu et al. 2015). This model suggests that the uptake heat of the adsorbate molecules in the biosorbed layer would decrease linearly with the coverage.

All the coefficients of the isotherm model related to the biosorption of EBT and MG dyes are given in Table 4. It was found that the $R^{2}$ values for the Freundlich model are relatively higher than those of the Langmuir and Temkin models. This suggests that the Freundlich model is more applicable for describing the EBT and MG adsorption isotherm data. This result is also supported by the lower $\Delta q$ and $\chi^{2}$ values. Moreover, the values of $n>1$ obtained from the Freundlich model signify that adsorption of EBT and MG dyes on TAS was favorable. Therefore, all these results signify that the biosorption process follows acceptably the Freundlich isotherm model in comparison to Langmuir and Temkin isotherm models, which suggests that the surface of TAS particles is heterogeneous and has an unequal distribution of binding energies on accessible active sites.

The maximum biosorption capacity $\left(q_{\mathrm{m}}\right)$ values, computed from the Langmuir model, of TAS particles and various adsorbents studied in the literature are summarized in Table 5. This study showed that the maximum biosorption capacity of TAS particles is 123.92 and $126.90 \mathrm{mg} \mathrm{g}^{-1}$ for EBT and MG, respectively. It can be seen that the TAS particles exhibit superior EBT and MG uptake capacity to that of previously reported adsorbents such as eucalyptus bark 
Table 3 Various calculated parameters of intraparticle diffusion model for various initial dye concentrations

\begin{tabular}{|c|c|c|c|c|c|c|c|c|}
\hline \multirow[t]{2}{*}{ Adsorbates } & \multirow{2}{*}{$\begin{array}{l}C_{0} \\
\left(\mathrm{mg} \mathrm{L}^{-1}\right)\end{array}$} & \multirow{2}{*}{$\begin{array}{l}q_{\mathrm{e}, \exp } \\
\left(\mathrm{mg} \mathrm{g}^{-1}\right)\end{array}$} & \multicolumn{6}{|l|}{ Intraparticle diffusion } \\
\hline & & & $k_{1 \mathrm{~d}}\left(\mathrm{mg} \mathrm{g}^{-1} \min ^{-1 / 2}\right)$ & $C_{1}\left(\mathrm{mg} \mathrm{g}^{-1}\right)$ & $R_{1}^{2}$ & $k_{2 \mathrm{~d}}\left(\mathrm{mg} \mathrm{g}^{-1} \min ^{-1 / 2}\right)$ & $C_{2}\left(\mathrm{mg} \mathrm{g}^{-1}\right)$ & $R_{2}^{2}$ \\
\hline \multirow[t]{5}{*}{ EBT } & 25 & 5.66 & 0.075 & 4.89 & 0.994 & 0.027 & 5.10 & 0.258 \\
\hline & 50 & 9.06 & 0.104 & 8.44 & 0.631 & 0.036 & 8.43 & 0.343 \\
\hline & 75 & 11.10 & 0.332 & 9.60 & 0.657 & -0.016 & 11.12 & 0.058 \\
\hline & 100 & 15.34 & 0.040 & 14.83 & 0.946 & 0.029 & 14.77 & 0.515 \\
\hline & 200 & 32.16 & 0.296 & 31.09 & 0.691 & -0.002 & 32.07 & - \\
\hline \multirow[t]{5}{*}{ MG } & 25 & 12.42 & 0.272 & 11.55 & 0.901 & 0.005 & 12.29 & 0.108 \\
\hline & 50 & 23.67 & 0.288 & 22.66 & 0.987 & 0.010 & 23.48 & 0.218 \\
\hline & 75 & 36.76 & 0.182 & 35.98 & 0.938 & 0.016 & 36.51 & 0.808 \\
\hline & 100 & 48.72 & 0.517 & 47.03 & 0.704 & 0.015 & 48.44 & 0.738 \\
\hline & 200 & 95.09 & 0.980 & 90.71 & 0.940 & 0.027 & 94.41 & 0.136 \\
\hline
\end{tabular}

(Dave et al. 2011), magnetite/pectin nanoparticles (Attallah et al. 2016), Avena sativa (oat) hull (Banerjee et al. 2016), and magnetic litchi pericarps (Zheng et al. 2015). Thus, these results show that TAS, which is a readily available and cheap by-product, can be utilized as a potential adsorbent to reduce the concentration of EBT and MG dyes from contaminated water.

\section{Biosorption thermodynamics}

Data were recorded at three temperatures: from 22 to $40{ }^{\circ} \mathrm{C}$. A decrease of the amount of EBT and MG dyes adsorbed onto TAS was observed with increasing temperature. This study shows that thermodynamic parameters including the changes in free energy $\left(\Delta G^{0}\right)$, enthalpy $\left(\Delta H^{0}\right)$, and entropy $\left(\Delta S^{0}\right)$ are pertinent parameters for the description of the thermodynamic behavior of the uptake of EBT and MG onto TAS.

For such equilibrium reactions, $K_{\mathrm{D}}$, the distribution constant, is given by (Barka et al. 2013)

$K_{\mathrm{D}}=q_{\mathrm{e}} / C_{\mathrm{e}}$.

The Gibbs free energy is

$\Delta G^{0}=-R T \ln K_{\mathrm{D}}$,

where $R$ is the universal gas constant $\left(8.314 \mathrm{~J} \mathrm{~mol} \mathrm{~K}^{-1}\right)$ and $T$ is solution temperature in kelvin.

The enthalpy $\left(\Delta H^{0}\right)$ and entropy $\left(\Delta S^{0}\right)$ of biosorption were estimated from the slope and intercept of the plot of $\ln K_{\mathrm{D}}$ versus $1 / T$, respectively.

$\ln K_{\mathrm{D}}=-\Delta G^{0} / R T=-\Delta H^{0} / R T+\Delta S^{0} / R T$.

The distribution coefficient, $K_{\mathrm{D}}$ of both dye systems decreased with elevating temperature, showing that the substantivity of EBT and MG dyes on TAS is highly dependent on temperature. High temperatures enhanced the solubility of pollutants in bulk solution much more than adsorbent particles (Chan et al. 2016). As shown in Table 6 , the negative enthalpy value $\left(\Delta H^{0}\right)$ indicates that the dye biosorption on TAS is exothermic. The typical value for physisorption usually lies below $80 \mathrm{~kJ} \mathrm{~mol}^{-1}$, which agrees with values obtained for adsorption of EBT and MG onto TAS. In addition, the negative entropy value $\left(\Delta S^{0}\right)$ reveals that the molecules of EBT and MG dyes in the adsorbed phase of TAS have lower randomness than pollutants molecules in bulk solution. The free energy changes $\left(\Delta G^{0}\right)$ are negative for MG, showing that the biosorption process is possible and spontaneous. In contrast, positive values of $\Delta G^{0}$ were obtained in this work for EBT with raising temperature. The positive $\Delta G^{0}$ shows that

Table 4 Isotherm parameters for EBT and MG adsorption onto TAS

\begin{tabular}{llcc}
\hline Isotherm & Parameter & EBT & MG \\
\hline \multirow{4}{*}{ Langmuir } & $q_{\mathrm{e}, \exp }\left(\mathrm{mg} \mathrm{g}^{-1}\right)$ & 15.34 & 48.72 \\
& $q_{\mathrm{m}}\left(\mathrm{mg} \mathrm{g}^{-1}\right)$ & 123.92 & 126.90 \\
& $k_{\mathrm{L}}\left(\mathrm{L} \mathrm{mg}^{-1}\right)$ & 0.002 & 0.291 \\
& $R^{2}$ & 0.8284 & 0.9730 \\
\multirow{5}{*}{ Freundlich } & $\chi^{2}$ & 0.035 & 0.539 \\
& $\Delta q(\%)$ & 3.35 & 7.84 \\
& $k_{\mathrm{F}}\left(\mathrm{L} \mathrm{mg}^{-1}\right)$ & 0.490 & 30.343 \\
& $n$ & 1.191 & 1.997 \\
\multirow{5}{*}{ Temkin } & $R^{2}$ & 0.9981 & 0.9999 \\
& $\chi^{2}$ & 0.012 & 0.001 \\
& $\Delta q(\%)$ & 1.98 & 0.30 \\
& $f$ & 0.0506 & 0.7259 \\
& $k_{\mathrm{T}}$ & 15.245 & 51.200 \\
& $R^{2}$ & 0.9376 & 0.9986 \\
& $\chi^{2}$ & 0.274 & 46.012 \\
& $\Delta q(\%)$ & 9.77 & 43.01
\end{tabular}


Table 5 Maximum adsorption capacities of EBT and MG on various adsorbents

\begin{tabular}{llcl}
\hline Dye & Sorbent & $q_{\mathrm{m}}\left(\mathrm{mg} \mathrm{g}^{-1}\right)$ & References \\
\hline EBT & Eucalyptus bark & 52.37 & Dave et al. (2011) \\
& Scolymus hispanicus L. & 120.42 & Barka et al. (2013) \\
& Magnetite/pectin nanoparticles & 103.41 & Attallah et al. (2016) \\
& Magnetite/silica/pectin nanoparticles & 80.15 & Attallah et al. (2016) \\
& Nteje clay & 16.26 & Elijah and Nwabanne (2014) \\
& Tunisian almond shell & 123.92 & This study \\
MG & 90.8 & Dahri et al. (2014) \\
& Walnut shell & 51.42 & Banerjee et al. (2016) \\
& Avena sativa (oat) hull & 60.97 & Wang et al. (2016) \\
& Polydopamine-chitosan nanoparticles & 62.71 & Hameed and El-Khaiary (2008) \\
& Rattan sawdust & 70.42 & Zheng et al. (2015) \\
& Magnetic litchi pericarps & 126.90 & This study \\
\hline
\end{tabular}

Table 6 Thermodynamic parameters for the adsorption of EBT and MG on TAS at different temperatures

\begin{tabular}{lllccc}
\hline Dye & $T\left({ }^{\circ} \mathrm{C}\right)$ & $K_{\mathrm{D}}$ & $\Delta G^{0}\left(\mathrm{~kJ} \mathrm{~mol}^{-1}\right)$ & $\Delta H^{0}\left(\mathrm{~kJ} \mathrm{~mol}^{-1}\right)$ & $\Delta S^{0}\left(\mathrm{~J} \mathrm{~mol}^{-1} \mathrm{~K}^{-1}\right)$ \\
\hline EBT & 22 & 0.221 & 3.70 & -1.71 & -0.02 \\
& 30 & 0.220 & 3.81 & & \\
& 40 & 0.213 & 4.03 & -32.04 & -0.08 \\
MG & 22 & 2.949 & -7.24 & & \\
& 30 & 2.385 & -6.01 & & \\
& 40 & 2.187 & -5.69 & & \\
\hline
\end{tabular}

the biosorption of EBT by TAS is a thermodynamically reversible, non-spontaneous, or unfavorable reaction. The increase in EBT and MG free energy values with the temperature augmentation suggested that the dye uptake was less favorable with increasing temperature.

\section{Conclusion}

TAS was identified as a suitable bioadsorbent for EBT and MG uptake in batch experiments. The batch study parameters, $\mathrm{pH}$ of solution, bioadsorbent particle size and dosage, contact time, initial dye concentration, and temperature were found to influence the uptake process. The $\mathrm{pH}$ experiments indicated that the major uptake takes place in the $\mathrm{pH}$ range 2-5 for EBT and 4-11 for MG. The adsorption rate was fast within $15 \mathrm{~min}$ and reached uptake equilibrium for both dyes. The adsorption kinetics and isotherm studies showed that uptake processes for both dyes are well fitted to pseudo-second-order kinetics and the Freundlich isotherm model. Thermodynamic studies confirmed that the uptake process was exothermic $\left(\Delta H^{0}<0\right.$ for EBT and MG). The biosorption of both dyes was accompanied by a decrease in the entropy due to the orderly arrangement of the dye molecules on the TAS surface. In addition, the negative values of $\Delta G^{0}$ proved the spontaneity of the MG uptake process. However, positive values of $\Delta G^{0}$ showed that the uptake of the EBT dye by TAS is not a spontaneous reaction. Moreover, the biosorption process may be realized at ambient temperatures $\left(\right.$ ca. $\left.22{ }^{\circ} \mathrm{C}\right)$ with best results.

Taking into consideration all the results obtained in this work, we concluded that the Tunisian almond shells may be used as alternatives to expensive adsorbents used for the removal of toxic dyes such as EBT and MG.

Acknowledgements The authors would like to thank the Higher Institute of Applied Sciences and Technology of Gabès for the financial support through the ISSATG Students program for innovation. The authors would like to thank Professor Abdessattar Aloui, Manel Hamdi (MSc student), and Haifa Chouki (MSc student) for their technical support.

\section{Compliance with ethical standards}

Conflict of interest On behalf of all authors, the corresponding author states that there is no conflict of interest.

\section{References}

Ali RM, Hamad HA, Hussein MM, Malash GF (2016) Potential of using green adsorbent of heavy metal removal from aqueous solutions: adsorption kinetics, isotherm, thermodynamic, 
mechanism and economic analysis. Ecol Eng 91:317-332. doi:10.1016/j.ecoleng.2016.03.015

Attallah OA, Al-Ghobashy MA, Nebsen M, Salem MY (2016) Removal of cationic and anionic dyes from aqueous solution with magnetite/pectin and magnetite/silica/pectin hybrid nanocomposites: kinetic, isotherm and mechanism analysis. RSC Adv 6:11461-11480. doi:10.1039/C5RA23452B

Banerjee S, Sharma GC, Gautam RK et al (2016) Removal of Malachite Green, a hazardous dye from aqueous solutions using Avena sativa (oat) hull as a potential adsorbent. J Mol Liq 213:162-172. doi:10.1016/j.molliq.2015.11.011

Barka N, Ouzaouit K, Abdennouri M, El M (2013) Dried prickly pear cactus (Opuntia ficus indica) cladodes as a low-cost and ecofriendly biosorbent for dyes removal from aqueous solutions. J Taiwan Inst Chem Eng 44:52-60. doi:10.1016/j.jtice.2012.09. 007

Bhatt AS, Sakaria PL, Vasudevan M et al (2012) Adsorption of an anionic dye from aqueous medium by organoclays: equilibrium modeling, kinetic and thermodynamic exploration. RSC Adv 2:8663. doi:10.1039/c2ra20347b

Calero M, Blázquez G, Ronda A et al (2013) Biosorption of $\mathrm{Cu}$ in a packed bed column by almond shell: optimization of process variables. Desalin Water Treat 51:1954-1965. doi:10.1080/ 19443994.2012.715167

Chairunnisa Siswanta D, Suratman A, Tanaka S (2016) Shirasu balloons and polydopamine-modified Shirasu balloons for adsorption of methylene blue. Water Air Soil Pollut 227:412. doi:10.1007/s11270-016-2898-8

Chan SL, Tan YP, Abdullah AH, Ong ST (2016) Equilibrium, kinetic and thermodynamic studies of a new potential biosorbent for the removal of Basic Blue 3 and Congo Red dyes: pineapple (Ananas comosus) plant stem. J Taiwan Inst Chem Eng 61:306-315. doi:10.1016/j.jtice.2016.01.010

Dahri MK, Kooh MRR, Lim LBL (2014) Water remediation using low cost adsorbent walnut shell for removal of malachite green: equilibrium, kinetics, thermodynamic and regeneration studies. J Environ Chem Eng 2:1434-1444. doi:10.1016/j.jece.2014.07. 008

Dave PN, Kaur S, Khosla E (2011) Removal of Eriochrome black-T by adsorption on to eucalyptus bark using green technology. Indian J Chem Technol 18:53-60

Dawood S, Sen TK (2012) Removal of anionic dye Congo red from aqueous solution by raw pine and acid-treated pine cone powder as adsorbent: equilibrium, thermodynamic, kinetics, mechanism and process design. Water Res 46:1933-1946. doi:10.1016/j. watres.2012.01.009

Deniz F (2013) Dye removal by almond shell residues: studies on biosorption performance and process design. Mater Sci Eng C 33:2821-2826. doi:10.1016/j.msec.2013.03.009

Dutta R, Nagarjuna TV, Mandavgane SA, Ekhe JD (2014) Ultrafast removal of cationic dye using agrowaste-derived mesoporous adsorbent. Ind Eng Chem Res 53:18558-18567. doi:10.1021/ ie5030003

Elijah OC, Nwabanne JT (2014) Adsorption studies on the removal of Eriochrome black-T from aqueous solution using Nteje clay. SOP Trans Appl Chem 1:14-25. doi:10.15764/STAC.2014. 02003

Freundlich HMF (1906) Über die adsorption in lösungen. Zeitschrift für Phys Chemie 57:385-470

Gautam RK, Rawat V, Banerjee S et al (2015) Synthesis of bimetallic $\mathrm{Fe}-\mathrm{Zn}$ nanoparticles and its application towards adsorptive removal of carcinogenic dye malachite green and Congo red in water. J Mol Liq 212:227-236. doi:10.1016/j.molliq.2015.09. 006
Hameed BH (2008) Equilibrium and kinetic studies of methyl violet sorption by agricultural waste. J Hazard Mater 154:204-212. doi:10.1016/j.jhazmat.2007.10.010

Hameed BH, El-Khaiary MI (2008) Malachite green adsorption by rattan sawdust: isotherm, kinetic and mechanism modeling. J Hazard Mater 159:574-579. doi:10.1016/j.jhazmat.2008.02. 054

Ho YS, McKay G (1999) Pseudo-second order model for sorption processes. Process Biochem 34:451-465. doi:10.1016/S00329592(98)00112-5

Kesraoui A, Moussa A, Ben Ali G, Seffen M (2016) Biosorption of alpacide blue from aqueous solution by lignocellulosic biomass: Luffa cylindrica fibers. Environ Sci Pollut Res 23:15832-15840. doi:10.1007/s11356-015-5262-4

Lagergren S (1898) Zur theorie der sogenannten adsorption gel ster stoffe. K Sven Vetenskapsakad Handl 24:1-39

Langmuir I (1918) The adsorption of gases on plane surfaces of glass, mica and platinum. J Am Chem Soc 40:1361-1403. doi:10.1021/ ja02242a004

Leng L, Yuan X, Zeng G et al (2015) Surface characterization of rice husk bio-char produced by liquefaction and application for cationic dye (Malachite green) adsorption. Fuel 155:77-85. doi:10.1016/j.fuel.2015.04.019

Li J, Huang Y, Liu Z et al (2015a) Chemical activation of boron nitride fibers for improved cationic dye removal performance. J Mater Chem A 3:8185-8193. doi:10.1039/C5TA00601E

Li Q, Tang X, Sun Y et al (2015b) Removal of Rhodamine B from wastewater by modified Volvariella volvacea: batch and column study. RSC Adv 5:25337-25347. doi:10.1039/C4RA17319H

Li Y, Meas A, Shan S et al (2016) Production and optimization of bamboo hydrochars for adsorption of Congo red and 2-naphthol. Bioresour Technol 207:379-386. doi:10.1016/j.biortech.2016. 02.012

Lin K, Pan J, Chen Y et al (2009) Study the adsorption of phenol from aqueous solution on hydroxyapatite nanopowders. J Hazard Mater 161:231-240. doi:10.1016/j.jhazmat.2008.03.076

Liu K, Li H, Wang Y et al (2015) Adsorption and removal of rhodamine B from aqueous solution by tannic acid functionalized graphene. Colloids Surf A Physicochem Eng Aspect 477:35-41. doi:10.1016/j.colsurfa.2015.03.048

Maaloul N, Oulego P, Rendueles M et al (2017) Novel biosorbents from almond shells: characterization and adsorption properties modeling for $\mathrm{Cu}(\mathrm{II})$ ions from aqueous solutions. J Environ Chem Eng 5:2944-2954. doi:10.1016/j.jece.2017.05.037

Módenes AN, Espinoza-Quiñones FR, Geraldi CAQ et al (2015) Assessment of the banana pseudostem as a low-cost biosorbent for the removal of reactive blue $5 \mathrm{G}$ dye. Environ Technol 36:2892-2902. doi:10.1080/09593330.2015.1051591

Mota TR, Kato CG, Peralta RA et al (2015) Decolourization of Congo Red by Ganoderma lucidum laccase: evaluation of degradation products and toxicity. Water Air Soil Pollut 226:351-361. doi:10.1007/s11270-015-2612-2

Özer A, Akkaya G, Turabik M (2005) The biosorption of Acid Red 337 and Acid Blue 324 on Enteromorpha prolifera: the application of nonlinear regression analysis to dye biosorption. Chem Eng J 112:181-190. doi:10.1016/j.cej.2005.07.007

Pavan FA, Camacho ES, Lima EC et al (2014) Formosa papaya seed powder (FPSP): preparation, characterization and application as an alternative adsorbent for the removal of crystal violet from aqueous phase. J Environ Chem Eng 2:230-238. doi:10.1016/j. jece.2013.12.017

Rahmat NA, Ali AA, Salmiati et al (2016) Removal of remazol brilliant blue $\mathrm{R}$ from aqueous solution by adsorption using pineapple leaf powder and lime peel powder. Water Air Soil Pollut. doi:10.1007/s11270-016-2807-1 
Saghanejhad Tehrani M, Zare-Dorabei R (2016) Highly efficient simultaneous ultrasonic-assisted adsorption of methylene blue and rhodamine $\mathrm{B}$ onto metal organic framework MIL-68(Al): central composite design optimization. RSC Adv 6:27416-27425. doi:10.1039/C5RA28052D

Santos SCR, Boaventura RAR (2016) Adsorption of cationic and anionic azo dyes on sepiolite clay: equilibrium and kinetic studies in batch mode. J Environ Chem Eng 4:1473-1483. doi:10.1016/j.jece.2016.02.009

Senturk HB, Ozdes D, Duran C (2010) Biosorption of Rhodamine 6G from aqueous solutions onto almond shell (Prunus dulcis) as a low cost biosorbent. Desalination 252:81-87. doi:10.1016/j. desal.2009.10.021

Temkin MJ, Pyzhev V (1940) Recent modifications to Langmuir isotherms. Acta Physicochim URSS 12:217-225

Wang Y, Zhang Y, Hou C, Liu M (2016) Mussel-inspired synthesis of magnetic polydopamine-chitosan nanoparticles as biosorbent for dyes and metals removal. J Taiwan Inst Chem Eng 61:292-298. doi:10.1016/j.jtice.2016.01.008

Weber W, Morris J (1963) Kinetics of adsorption on carbon from solution. J Sanit Eng Div 89:31-60

Xiao S, Gao R, Lu Y et al (2015) Fabrication and characterization of nanofibrillated cellulose and its aerogels from natural pine needles. Carbohydr Polym 119:202-209. doi:10.1016/j.carbpol. 2014.11.041

Zhang Z, Moghaddam L, O'Hara IM, Doherty WOS (2011) Congo Red adsorption by ball-milled sugarcane bagasse. Chem Eng $\mathrm{J}$ 178:122-128. doi:10.1016/j.cej.2011.10.024

Zheng H, Qi J, Jiang R et al (2015) Adsorption of malachite green by magnetic litchi pericarps: a response surface methodology investigation. J Environ Manage 162:232-239. doi:10.1016/j. jenvman.2015.07.057 